\title{
Editorial \\ New data favouring that neurotrophins are of importance in arthritis
}

Sture Forsgren

Department of Integrative Medical Biology, Anatomy Section, Umeå University, SE-901 87 Umeå, Sweden

Corresponding author: Sture Forsgren, sture.forsgren@anatomy.umu.se

Published: 30 July 2009

Arthritis Research \& Therapy 2009, 11:122 (doi:10.1186/ar2754)

This article is online at http://arthritis-research.com/content/11/4/122

(c) 2009 BioMed Central Ltd

See related research by Barthel et al., http://arthritis-research.com/content/11/3/R82

\begin{abstract}
Neurotrophins are important in inflammation. In an article in Arthritis Research \& Therapy, Barthel and collaborators give new information on the existence of neurotrophin production in the synovial tissue of arthritic joints. These findings, together with other recent findings, stress that neurotrophins should be considered important factors in arthritis. This is reinforced by the facts that they are also produced by articular chondrocytes and that receptors for these are present in the synovial tissue and on chondrocytes. The importance of neurotrophins in joints should be further studied, including examinations on the efficacy of interfering with their effects in arthritis.
\end{abstract}

In an article in Arthritis Research \& Therapy, Barthel and colleagues have described that cellular mRNA expressions for the neurotrophins nerve growth factor (NGF) and brainderived neurotrophic factor (BDNF) are detectable both in the synovial tissue and in the synovial fluid of arthritic patients [1]. The expression for NGF was particularly noteworthy in samples of patients with rheumatoid arthritis. NGF was not expressed in fibroblast-like synoviocytes, as seen by ELISA analysis on culture supernatant. The authors concluded that infiltrating $\mathrm{T}$ lymphocytes and myeloid cells are the main sources of NGF in the inflamed peripheral joint. Nevertheless, the authors do not rule out the possibility that fibroblast-like synoviocytes can produce NGF under certain circumstances.

These findings give new evidence for the importance of neurotrophins for the inflammatory process in arthritis. The group of neurotrophins, which apart from NGF and BDNF is constituted of neurotrophin 3 and neurotrophin 4, has been considered of importance in various types of inflammatory conditions. In particular, NGF has been detected at high levels in regions with inflammation. Accordingly, there are high levels of NGF in the synovial fluid of rheumatoid arthritis patients. Neurotrophins are also of importance as factors that promote growth and survival of neurons, and they may be involved in the pathogenesis of pain.

In accordance with the findings of Barthel and collaborators [1], immunoreactions for NGF and BDNF have been found in the inflammatory infiltrates of the synovial tissue of arthritic mice but not in the synovial tissue of healthy mice [2]. Furthermore, cells in cultures of human synovial cells can produce NGF [3], and immunoreactions for BDNF have been detected in macrophages as well as in fibroblast-like synoviocytes in the synovial tissue of rheumatoid arthritis patients [4]. Of further importance is the fact that immunoreactions for neurotrophins are also detectable in nerve structures of the synovial tissue [2,5]. Immunoreactions for NGF and BDNF are also detectable on chondrocytes, including articular chondrocytes, as seen in studies on mouse joints [2].

Functional effects of neurotrophins are likely to occur within the synovial tissue. Expressions of the low-affinity neurotrophin receptor p75 as well as the high-affinity neurotrophin receptor TrkA are therefore present in the synovial tissue of patients with spondyloarthritis [6]. Immunoreactions for p75 and the high-affinity receptor TrkB are also present in the synovial tissue of rheumatoid arthritis patients, the receptors being located in relation to the nerve structures [5]. The results of a recent study suggest there is an upregulation of NGF/TrkA in cytokine-activated fibroblast-like synoviocytes, suggesting that there is a cross-talk between NGF and its receptors in inflammatory arthritis [7]. Autocrine/paracrine effects of neurotrophins also appear to occur concerning the articular chondrocytes [2].

The effects of NGF in the inflamed synovium can be either proinflammatory or protective and regenerative. There is thus evidence that points in both directions. Interestingly, topical 
application of NGF to human corneal and skin ulcers can have healing actions [8] and, as seen in studies on rat injured ligaments, local application of NGF may improve the healing process [9]. Nevertheless, NGF does also have proinflammatory effects. One possibility is that the effects of NGF in relation to inflammations vary over time, and furthermore that NGF actually is related to the modulation of and not the induction of the inflammation of joints [3].

Interestingly, neurotrophins have a relationship to TNF $\alpha$. The production of both NGF and BDNF can thus be stimulated by TNF $\alpha$. An effect on BDNF levels has been shown in response to anti-TNF treatment. The BDNF levels in plasma were found to be decreased in response to this treatment [5], a finding that is supported by the observation of a tendency for a decrease in plasma BDNF levels after anti-TNF treatment in a previous preliminary report [10]. Furthermore, the degrees of TrkA and p75 immunoreactions in spondyloarthritis synovitis were reported to be downregulated by anti-TNF treatment [6]. It cannot be excluded that the effects of anti-TNF treatment on BDNF levels are not only related to effects on local cells in the synovium, but also to effects on circulating cells and/or BDNF-containing neurons [5].

The results in the recent study by Barthel and collaborators and those obtained in other recent studies show collectively that neurotrophins should be further considered as factors of relevance in arthritic inflammation. It might be that the effects of these should be interfered with in arthritis. Further studies are needed in order to clarify whether antagonists or agonists to NGF (or to BDNF) should be applied.

\section{Competing interests}

The author declares that they have no competing interests.

\section{References}

1. Barthel C, Yeremenko N, Jacobs R, Schmidt RE, Bernateck M, Zeidler H, Tak P-P, Baeten D, Rihl M: Nerve growth factor and receptor expression in rheumatoid arthritis and spondyloarthritis. Arthritis Res Ther 2009, 11:R82.

2. Grimsholm O, Guo Y, Ny T, Forsgren S: Expression patterns of neurotrophins and neurotrophin receptors in the articular chondrocytes and the inflammatory infiltrates in knee joint arthritis. Cells Tissues Organs 2008, 188:299-309.

3. Manni L, Lundeberg T, Fiorito S, Bonini S, Vigneti E, Aloe L: Nerve growth factor release by human synovial fibroblasts prior to and following exposure to tumor necrosis factoralpha, interleukin-1 beta and cholecystokinin-8: the possible role of NGF in the inflammatory response. Clin Exp Rheumatol 2003, 21:617-624.

4. Weidler C, Holzer C, Harbuz M, Hofbauer R, Angele $P$, Scholmerich J, Straub RH: Low density of sympathetic nerve fibres and increased density of brain derived neurotrophic factor positive cells in RA synovium. Ann Rheum Dis 2005, 64: 13-20.

5. Grimsholm O, Rantapää-Dahlqvist S, Dalén T, Forsgren S: BDNF in RA: downregulated in plasma following anti-TNF treatment but no correlation with inflammatory parameters. Clin Rheumato/ 2008, 27:1289-1297.

6. Rihl M, Kruithof E, Barthel C, De Keyser F, Veys EM, Zeidler H, Yu DT, Kuipers JG, Baeten D: Involvement of neurotrophins and their receptors in spondyloarthritis synovitis: relation to inflammation and response to therapy. Ann Rheum Dis 2005, 64:1542-1549.
7. Raychaudhuri SP, Raychaudhuri SK: The regulatory role of nerve growth factor and its receptor system in fibroblast-like synovial cells. Scand J Rheumatol 2009, 38:207-215.

8. Aloe L, Tirassa P, Lambiase A: The topical application of nerve growth factor as a pharmalogical tool for human corneal and skin ulcers. Pharmacol Res 2008, 57:253-258.

9. Mammoto T, Seerattan RA, Paulson KD, Leonard CA, Bray RC, Salo PT: Nerve growth factor improves ligament healing. J Orthop Res 2008, 26:957-964.

10. del Porto F, Aloe L, Lagana B, Triaca V, Nofroni I, DÁmelio R: Nerve growth factor and brain-derived neurotrophic factor levels in patients with rheumatoid arthritis treated with TNF- $\alpha$ blockers. Ann NY Acad Sci 2006, 1069:438-443. 